\title{
PIK3R1 Gene Mutation
}

National Cancer Institute

\section{Source}

National Cancer Institute. PIK3R1 Gene Mutation. NCI Thesaurus. Code C132894.

A change in the nucleotide sequence of the PIK3R1 gene. 